\title{
Trends in COVID-19 Vaccine Intentions during the COVID-19 Pandemic; a Systematic Review and Meta-Analysis of Cross-Sectional Studies
}

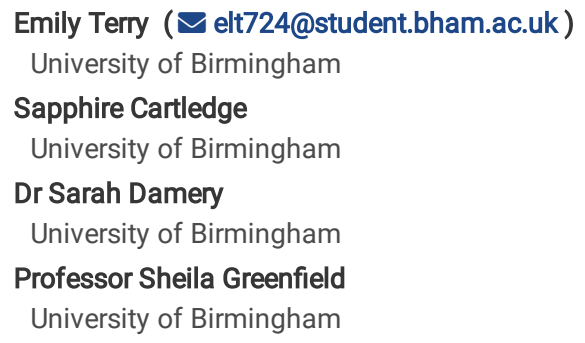

\section{Research Article}

Keywords: Vaccine, Vaccine Intentions, Vaccine Hesitancy, COVID-19, Coronavirus; Pandemic, Health Behaviour, Public Health, Attitudes to Health

Posted Date: September 17th, 2021

DOI: https://doi.org/10.21203/rs.3.rs-870761/v1

License: () (1) This work is licensed under a Creative Commons Attribution 4.0 International License. Read Full License 


\section{Abstract}

\section{Background}

A high COVID-19 vaccine uptake is essential to achieve herd immunity to combat the current strain of COVID-19 and potential future variants. This review aimed to identify factors associated with public intention to receive COVID-19 vaccines until February 2021 to provide accessible data to policymakers to inform framing and targeting of messages designed to optimise vaccine uptake.

\section{Methods}

Medline, Embase, CINAHL, PsycINFO, PsycARTICLES, Sociological Abstracts and Applied Social Sciences Index and Abstracts were searched for crosssectional studies reporting data regarding COVID-19 vaccine intentions, published between 01/01/2020 and 12/02/2021. Title/abstract and full-text screening were performed independently by two authors. The Appraisal Tool for Cross-sectional Studies (AXIS) was used to assess bias and quality. Both randomeffects meta-analysis and narrative synthesis were used to describe vaccine intentions and associated factors. A subgroup analysis assessing the impact of sex, sampling method and time of survey on COVID-19 vaccine intention was performed.

\section{Results}

Searches identified 4739 studies, and 23 cross-sectional studies were deemed eligible for the review; 22 used online surveys and one used a mixed-methods study design. Eighteen surveys were conducted in the first half of 2020 and five were conducted in the latter half of 2020. Fifteen countries were represented, with the most common being the United States $(n=4)$ and the United Kingdom $(n=4)$ sampling 41403 participants across all surveys. Most studies employed convenience sampling and 11 non-responder rates raised concerns over non-response bias. From the 18 studies included in the meta-analysis, the pooled proportion of survey participants willing to receive the COVID-19 vaccine was $73.3 \%$ ( $n=18,95 \%$ Confidence Interval $64.2 \%$ to $81.5 \%, I^{2}=99.7 \%$ ). Factors associated with a higher COVID-19 vaccine acceptance included greater perceived risk of COVID-19, lower level of perceived vaccine harm, higher educational attainment and household income, older age, being of White ethnicity and male sex.

\section{Conclusions}

There was a high willingness to receive the COVID-19 vaccine which was influenced by multiple sociodemographic factors and individual risk perceptions. The findings suggest that future research should explore the reasoning behind vaccine intentions for different sociodemographic groups to allow targeted communication strategies to be formulated by public health agencies.

\section{Background}

Since coronavirus disease 2019 (COVID-19) was first identified in Wuhan, China in December 2019 ${ }^{1}$, there have been numerous coronavirus case surges around the globe ${ }^{2}$. The development of effective COVID-19 vaccines has given hope to the global community, with the vaccine rollout marking a 'turning point' in the battle against coronavirus ${ }^{3}$.

Mass vaccination programmes aim to vaccinate a large proportion of the population so that disease transmission is slowed and vulnerable individuals who cannot be vaccinated are still protected ${ }^{4}$. This phenomenon is known as herd immunity and can only be achieved when a substantial proportion of the population is vaccinated ${ }^{5}$. The threshold to achieve herd immunity against COVID-19 is estimated at between $60-70 \%{ }^{4}$. However, due to the viral nature of COVID-19, mutations are inevitable and the main 'Delta' variant in India has taken over as the dominant strain in many countries ${ }^{6}$. New variants may be more transmissible which will require a higher herd immunity threshold, and/or more likely to cause severe infection ${ }^{7}$. The situation is constantly evolving hence a high vaccine uptake is essential to combat the current dominant strain of COVID-19 and any potential future strains ${ }^{8}$

Global public trust in governments has rapidly declined throughout the pandemic, with the Edelman Trust Barometer reporting a significant decline in trust between both the Chinese and American government and their own citizens between May 2020 and January $2021^{9}$. Together with the increasingly prominent role of social media, pandemics are a breeding ground for fearmongering and rumours to circulate ${ }^{10}$. Online misinformation circulating on social media regarding COVID-19 is a growing problem ${ }^{11}$. In the case of COVID-19 (as in past pandemics), the dissemination of vaccine misinformation has been particularly prevalent in fuelling a growing anti-vaccination movement ${ }^{12,13}$. A recent analysis of social media identified that $39 \%$ of online rumours regarding the COVID-19 pandemic were about the COVID-19 vaccine, with $76 \%$ of such rumours reported to be false ${ }^{14}$.

The term 'vaccine hesitancy' refers to a delayed acceptance or complete refusal of a vaccine ${ }^{15}$. The effects of vaccine hesitancy can be devasting. The diphtheria-tetanus-pertussis (DTP) vaccine was routinely used in the UK for over 20 years ${ }^{16}$. However, following the publication of case-series linking the vaccine to a rare neurological side-effect, there was a dramatic fall in immunisation rates against DTP from $77-33 \% 16,17$. This was followed by three whooping-cough epidemics in the $\mathrm{UK}^{17}$. Therefore, historic evidence suggests that uncertain times can increase individual and societal vaccine hesitancy.

Many factors may contribute to vaccine hesitancy ${ }^{15}$. A systematic review of adults aged 65 years and older in the United States of America (USA) identified female sex, older age, higher education, higher household income and White ethnicity all increase the likelihood of seasonal influenza vaccination uptake ${ }^{18}$. It is currently unclear whether COVID-19 vaccine intentions are influenced by the same trend in socio-demographic factors. Public Health England (PHE) reported large disparities in mortality and morbidity risks of COVID-19 infection between different sociodemographic groups, with more deprived areas and ethnic minority individuals (particularly Black ethnic groups) shown to be at a higher risk ${ }^{19}$. Arguably, these groups would benefit the most from the COVID-19 vaccine. 
Since the beginning of the COVID-19 pandemic, several systematic reviews have been conducted into COVID-19 vaccine uptake and adherence ${ }^{20-24}$.

Lin et al. (December 2020) evaluated 126 cross-sectional surveys of vaccine intentions dating from February to October $2020^{20}$. A narrative synthesis of results described a declining trend in vaccine intention and highlighted socioeconomic and ethnic issues pertaining to vaccine availability. Due to the dynamic nature of public opinion during the pandemic, the review recommends continuous monitoring of vaccine intentions, especially following the introduction of mass-vaccination programmes.

Robinson et al. (December 2020) published a smaller review of 28 international cross-sectional studies and survey dates ranged from March-October ${ }^{21}$. The review reported a high rate of vaccine intention across survey participants (72.9\% of total participants were prepared to have a COVID-19 vaccine, $95 \%$ confidence interval $(\mathrm{Cl}) 66.6-78.4 \%, \mathrm{I}^{2}=99.6 \%$ ) and found a declining trend in vaccine willingness over time. It searched only two online databases and only one author conducted all stages of screening and data extraction. Limited database searching can introduce selection bias ${ }^{25}$ and the absence of conventional double screening can result in the omission of key studies ${ }^{26}$. This review included surveys with a large sample size only $(n \geq 100)^{24}$, compared to Lin et al.'s review which included surveys with smaller sample sizes ${ }^{23}$. Overall, the review conducted by Robinson et al. provides a systematic summary of the global populations' acceptance towards the COVID-19 vaccine up until October $2020^{21}$.

Given the rapidly evolving course of the pandemic, ongoing research is needed to reflect the changing evidence base and summarise public opinion later in the pandemic. Therefore, this systematic review will provide an updated summary of public opinion towards the COVID-19 vaccine around the globe up until February 2021, with the intention of providing readily accessible data to policymakers.

Aims

This review aimed to assess: (1) general population intention to receive the COVID-19 vaccine around the world up until February 2021 and changes over time; (2) factors associated with COVID-19 vaccine acceptance; (3) reasons behind individuals' vaccination intention.

\section{Methods}

Eligibility Criteria

As recommended by the Cochrane Collaboration, the research question and eligibility criteria were framed using the SPIDER search tool, to maintain a focused review $(\text { Table } 1)^{27}$.

Table 1

Eligibility criteria for the research question

\begin{tabular}{|c|c|}
\hline SPIDER & EXPLANATION \\
\hline \multirow[t]{2}{*}{ Sample } & Adults from the general population. \\
\hline & $\begin{array}{l}\text { Studies were excluded if limited to healthcare professionals and medical students only as this would have restricted the generalisability } \\
\text { of the review findings to the general population. }\end{array}$ \\
\hline $\begin{array}{l}\text { Phenomenon } \\
\text { of Interest }\end{array}$ & $\begin{array}{l}\text { Beliefs about the COVID-19 vaccine including, but not limited to, vaccine hesitancy or acceptance, factors influencing acceptance and } \\
\text { reasoning behind vaccine intentions. }\end{array}$ \\
\hline Design & Cross-sectional studies based on survey data. \\
\hline \multirow[t]{5}{*}{ Evaluation } & Surveys must have reported some metric relating to COVID-19 vaccine intentions and/or respective determinants and/or reasoning. \\
\hline & This includes any type of COVID-19 vaccine. \\
\hline & This must have been presented as extractable raw data. \\
\hline & Where sociodemographic factors were reported, data on these were extracted for analysis. \\
\hline & Studies must have detailed the specific survey questions used to assess attitudes, to allow for appropriate analysis. \\
\hline \multirow{2}{*}{$\begin{array}{l}\text { Research } \\
\text { Type }\end{array}$} & Studies published in peer-reviewed journals were eligible for inclusion. \\
\hline & $\begin{array}{l}\text { Unpublished journal articles were not included due to the low quality of data they were likely to provide, affecting the validity of the } \\
\text { analysis and discussion. Grey literature was not included, as due to the high level of misinformation surrounding the subject of COVID-19 } \\
\text { it would have been inappropriate to include this datatype in the evidence base of the systematic review. This did not limit the } \\
\text { generalisability of the literature search, as the initial scoping searches retrieved } 19 \text { cross-sectional studies, published in peer-reviewed } \\
\text { journals. Editorials, reviews, or commentaries were excluded. Dissertations and theses were not considered as there would have been no } \\
\text { literature available in this evidence area due to the recent emergence of COVID-19. }\end{array}$ \\
\hline
\end{tabular}

Search Methods

This review was developed and structured in line with the 2020 Preferred Reporting Items for Systematic Reviews (PRISMA) guidelines ${ }^{28}$.

\section{Information Sources}

A literature search of Medline (Ovid) ${ }^{29}$, Embase (Ovid) ${ }^{30}$ and CINAHL (EBSCO) ${ }^{31}$ was undertaken by one author (ET). Specialist social sciences databases were also searched: APA PsycINFO (Ovid) ${ }^{32}$, APA PsycARTICLES (Ovid) ${ }^{33}$, Sociological Abstracts (ProQuest) ${ }^{34}$ and Applied Social Sciences Index and 
Abstracts (ASSIA, ProQuest) ${ }^{35}$.

\section{Search Strategy}

Search strategy development was guided by a librarian specialist. Several scoping searches were conducted on Medline ${ }^{29}$ and Embase $\mathrm{E}^{30}$ to identify relevant literature and understand any differences in standardised subject terms across the databases. Development of search terms were guided by the results of the scoping review. The search strategy was subsequently piloted using Medline ${ }^{29}$ and refined until all key papers identified in the scoping review were retrieved from the first 100 search results. A combination of text words and standardised subject terms were used, adjusted for each database, to avoid missing key literature.

For the purpose of this review, studies investigating vaccine intentions were included, with vaccine hesitancy defined as "a delay in acceptance or refusal of vaccination despite availability of vaccination services" 36 and vaccine acceptance defined as "outcome behaviour resulting from a complex decision-making process that can be potentially influenced by a wide range of factors" ${ }^{36}$. We searched explicitly for papers that included data on these terms, using the search terms 'COVID-19', 'Pandemics', 'Intention', 'Attitude to Health', 'Mass Vaccination', 'Vaccination Refusal', 'Anti-Vaccination Movement' and 'Vaccination'. Search terms were combined with the Boolean operators 'AND' or 'OR', the explosion function was used where possible, and truncation was utilised to capture all alternative spellings of the terms. Searches were conducted on 12/02/2021.

\section{Limits}

Date of publication was limited from 1st January 2020 to the day the search was undertaken. The study-type was limited to cross-sectional studies. No geographical limits were applied, but only studies published in English were eligible.

\section{Data Management}

Endnote was used to store references and remove duplicates automatically ${ }^{37}$. The web-based reviewing platform Rayann was used for title/abstract and fulltext screening ${ }^{38}$.

\section{Selection Process}

Title and abstract screening were performed independently by two authors (ET and SC), who both performed full-text assessment of potentially eligible studies (Table 1). All discrepancies in inclusion/exclusion decisions at both stages of screening were discussed by ET and SC over the online video platform Zoom initially and with SD as a third reviewer when a decision could not be made ${ }^{39}$. As screening was undertaken by two novice reviewers, inter-rater reliability was measured using Cohen's Kappa coefficient at both stages, with a Kappa value of $>0.6$ deemed to represent substantial agreement ${ }^{40}$.

Data Extraction and Synthesis

\section{Data Collection Process}

A data extraction form (Additional File 4) was developed and piloted prior to use. Data were extracted by ET and a random sample of $10 \%$ of studies was coassessed by SD, to minimise data extraction errors. Any differences of opinions were discussed, to ensure that all relevant data were extracted. For each study, study characteristics were extracted including study design, sample size, location, survey timescale, method of recruitment, participant demographics, validation and standardisation of the survey instruments, the specific survey questions used to capture attitudes towards the COVID-19 vaccine, response scales, recorded proportions of vaccine intentions and any other relevant information.

\section{Risk of Bias and Quality Assessment}

Study quality and risk of bias were assessed using the Appraisal Tool for Cross-Sectional Studies (AXIS) (Additional File 5$)^{41}$ which was piloted for suitability on two studies. ET assessed all studies, with $10 \%$ co-assessed independently by a second author (SC). Again, Cohen's Kappa coefficient was calculated to test inter-rater reliability.

\section{Data Synthesis}

Data were summarised using narrative syntheses and meta-analyses as appropriate. Where response proportions were represented as raw numbers, data were converted to percentages of total survey participants in each included study.

All studies were assessed to determine whether it was appropriate to statistically combine the survey findings. Guided by Lin at al., surveys were excluded from analysis if questions included persuasive or influencing language; if they included phrases similar to 'if a safe and effective vaccine was available' 20 The remaining surveys were included in a random-effects meta-analysis using the 'metaprop' comman ${ }^{42}$, to estimate the proportion of total survey participants reporting vaccine acceptance (including 95\% confidence intervals). For studies that included a 5-point Likert scale, vaccine acceptance represented the proportions of both 'strongly agree' and 'agree' responses. Percentage proportions were presented using forest plots, including statistical heterogeneity. Substantial heterogeneity $\left(1^{2}>85 \%\right)$ was expected due to the nature of the survey outcome; an individual's decision on vaccine uptake may be influenced by multiple and potentially overlapping factors simultaneously. Publication bias was not assessed; instead, sub-group analyses of the metaregression by sample size ( $\mathrm{n}<1,000$ vs $n \geq 1,000)$ and sampling method (non-probability vs probability sampling) were performed.

Across studies that included four response categories (variations of 'strongly agree', 'agree', 'disagree' and 'strongly disagree'), the mean proportion of responses in each category were compared. Across studies that included a hesitant response category (variations of 'maybe'), the overall proportion of survey participants reporting COVID-19 vaccine hesitant and improbable/very improbable were compared. 
For all studies, the influence of health beliefs and sociodemographic variables (age, gender, ethnicity, education, and income level) on vaccine acceptance, and reasons for vaccine hesitancy were summarised narratively. Of the studies included in the meta-regression, further sub-group analyses of participants reporting vaccine acceptance by gender and time of survey were performed on studies that reported the relevant data.

Statistical significance for all analyses was set at the $5 \%$ level $(p=0.05)$ and all statistical analyses were conducted using STATA16 ${ }^{42}$.

\section{Results}

Study Selection

The literature search returned 5447 studies and following removal of duplicates, 4739 studies were considered for title and abstract screening. Following title and abstract screening, 55 full-text articles were assessed for eligibility. Of these, 23 studies met the inclusion criteria and were deemed eligible for the review ${ }^{43-65}$. Reasons for exclusion at full-text screening included a lack of specific focus on the COVID-19 vaccine and the absence of extractable raw data (Fig. 1). Cohen's Kappa was 0.7 at title and abstract screening and 0.8 at full-text screening.

Summary of Included Studies

All studies had a cross-sectional study design: 22 used online surveys $\mathrm{s}^{43-46,48-65}$ and one study used a mixed-methods approach, including both an online survey and semi-structured interviews ${ }^{47}$. Eighteen surveys were conducted in the first half of 2020 (January-June) ${ }^{43-46,48-53,55-58,62-65}$ and five were conducted in the latter half of 2020 (July-December) $45,54,59-61$. Fifteen countries were represented in the review, the commonest being the USA ( $\mathrm{n}=4)^{50,54,58,59}$ and the UK $(n=4)^{47,56,61,63}$. In total, 41,403 participants were sampled across all surveys, with sample sizes ranging from $525^{54}$ to $5677^{44}$ participants. The majority of participants were aged between 25-50 years old, and all surveys reported a higher proportion of female participants with one exception ${ }^{54}$. Ethnicity data were only reported in nine studies $47,50,54,56-59,61,64$, with Black, Asian and Minority Ethnic (BAME) representation ranging from $3.6 \%{ }^{64}$ to $36.7 \% 50$ (Additional File 1).

Survey questions used to assess vaccination intentions could largely be categorised into two; 18 studies used neutral questions such as 'Will you get the coronavirus vaccine when available?' 43,46-50,52-55,57,58,60-64; five studies used persuasive language that may have potentially influenced self-reported vaccine acceptance, for example 'If a new vaccine for COVID-19 was released that was proven to be safe and effective, I would get vaccinated immediately'44,45,56,59,65. Fifteen studies recorded responses using a Likert-scale, adopting variations of the terms 'Strongly Agree to Disagree ${ }^{\prime 43-45,47,49,53,55,58,59,61-65}$, seven studies utilised a simple 'Yes', 'No' and/or 'Maybe' response scale $46,48,50-52,56,57,60$ and one study used a best-fit statement response ${ }^{54}$ (Additional File 2).

Quality Assessment and Risk of Bias

Of the 23 studies included in the review, 17 studies used piloted, trialled or previously published survey instruments (Additional File 3 ) 43,44,47,48, 50-61,64,65. Only 11 studies used an adequate sampling frame to achieve a representative sample $45,46,50,51,54-56,58,59,61,62$ and 10 studies were deemed to use an adequate selection process ${ }^{47,50,51,54-57,59,61,62}$. Of the studies that used adequate sampling frames, eight used existing online research panels ${ }^{46,50,54,56,58,59,61,62}$ (two most common being Qualtrics, $n=2^{54,56}$ and the AmeriSpeak panel, $n=2^{50,59}$ ). Sixteen studies did not categorise non-responder rates ${ }^{43,45,47-}$

49,51,52,54,56,58,60-64 and 11 non-responder rates raised concerns over non-response bias $44-46,49,53,55,59,60,62,63,65$. Non-responder bias could not be determined for six studies due to lack of adequate information ${ }^{43,48,52,56,61,62}$.

Vaccine Intentions

Five studies were removed from the meta-analysis due to the use of persuasive questions to assess vaccine intentions ${ }^{44,45,56,59,65}$. From the 18 studies included in the meta-analysis, the pooled proportion of survey participants willing to receive the COVID- 19 vaccine was $73.3 \%\left(n=18,95 \% \mathrm{Cl} 64.2-81.5 \%, \mathrm{I}^{2}=\right.$ $99.7 \%, p=0.00$ Fig. 2) $43,46-50,52-55,57,58,60-64$. Only two studies included in the meta-analysis reported a higher proportion of participants unwilling to receive the vaccine $\left(71.3 \%\right.$ in Sallam et al. ${ }^{60}$ and $51.9 \%$ in Mouchtouri et al). ${ }^{55}$

Across the 10 studies that included four response categories (variations of 'strongly agree', 'agree', 'disagree' and 'strongly disagree'), individuals were more confident in accepting the vaccine than rejecting the vaccine ${ }^{43-45,47,49,53,55,58,63,64}$. A mean proportion of $51.3 \%$ participants were definitely willing, compared to only $30.7 \%$ participants possibly willing to receive the COVID-19 vaccine. Contrastingly, a higher proportion of participants reported improbable rather than very improbable intentions to receive the COVID-19 vaccine, a mean proportion of $6.0 \%$ and $4.9 \%$ respectively.

Across the 15 studies that included a hesitant response choice (variations of 'maybe'), participants were more likely to be vaccine hesitant than either improbable/very improbable, with a mean proportion of $22.2 \%$ and $9.4 \%$ respectively $43-45,49,50,55-59,61,63-65$.

Factors Associated with Vaccine Intentions

\section{Health Beliefs}

A lower perceived individual risk and perceived severity of COVID-19, lower levels of worry regarding the pandemic and lower perceived likelihood of becoming infected with COVID-19 were all found to be major variables reducing vaccine acceptance in all eight studies investigating these factors $46,49,53,57,58,62,64,65$. One survey reported that personal fear about COVID-19 meant the individual was almost 2.5 times significantly more likely to accept the vaccine (Odds Ratio (OR) $2.5,95 \% \mathrm{Cl} 2.0-3.0, \mathrm{p}<0.001)$ compared to individuals with no fear ${ }^{49}$. Additionally, positive attitudes towards past influenza vaccines significantly increased 
the likelihood of COVID-19 vaccine acceptance ${ }^{46,50,61}$. Higher levels of perceived vaccine harm, concerns about side-effects and vaccine efficacy significantly contributed to a reduced vaccine acceptance in four out of four studies $53,58,61,64$. One survey reported a significant increase in the likelihood of vaccine acceptances if individuals perceived the vaccine to reduce the risk of COVID-19 infection (OR 3.1, 95\% $\mathrm{Cl} 2.1$ to $4.8, \mathrm{p}<0.001)^{53}$.

\section{Sociodemographic Variables}

\section{Sex}

Males were significantly more willing to receive the COVID-19 vaccine than females in all seven studies investigating this variable ${ }^{46,50,53,58,60,62,64}$. One survey reported that males were almost twice as likely as females to receive the COVID-19 vaccine (OR $1.9,95 \% \mathrm{Cl} 1.5-2.3, \mathrm{p}<0.001)^{49}$. A subgroup analysis by gender across the seven studies reporting gender proportions revealed a similar trend; the pooled proportion willing to vaccinate for males was $71.9 \%$ ( $95 \% \mathrm{Cl}$ 59.4-83.0\%) and 58.0\% (95\% Cl 37.1-77.4\%) for females, but this was not statistically significant $(p=0.247, \text { Fig. 3) })^{46,50,53,58,60,62,64}$. Similarly, females were consistently recorded as more likely to be vaccine hesitant than their male counterparts ${ }^{45,46,56}$ with an Australian survey recording females as almost twice as likely to be vaccine hesitant than males (Relative Risk Ratio (RRR) $=2.0,95 \% \mathrm{Cl} 1.5$ to $2.6, \mathrm{p}<0.001)^{46}$.

\section{Ethnicity}

BAME individuals reported lower vaccination intentions than White individuals in all four studies that assessed acceptance by ethnicity $47,50,56,58$. Specifically, individuals of Black ethnicity were reported to be less accepting than White ethnic individuals in both studies investigating specific ethnicities ${ }^{50,58}$ and less accepting than both Hispanic and White ethnic individuals in one survey ${ }^{58}$. One study reported Black individuals to be up to 6.4 times more likely to be either hesitant or resistant (RRR 6.4, 95\% $\mathrm{Cl} 3.2$ to 13.0 , no p-value reported) than their White counterparts ${ }^{50}$.

\section{Household Income}

Individuals with a lower household income were significantly less willing to receive the vaccine in three out of four studies ${ }^{47,54,58}$. One study reported that lower income households were over two times more likely to reject the vaccine than higher income households $(\mathrm{OR} 2.1,95 \% \mathrm{Cl} 1.3-3.3, \mathrm{p}<0.001)^{47}$. However, one survey appeared to contradict this trend, suggesting that individuals in the lowest income band were significantly more likely to express vaccine hesitancy than rejection compared to individuals in higher income brackets ${ }^{56}$.

\section{Educational Attainment}

In all three studies investigating education, lower education was associated with lower vaccine acceptance ${ }^{45,50,60}$. In one study, the risk of individuals with no high school diploma rejecting and/or hesitating over the vaccine was almost eight times higher than those with a diploma or higher (RRR 7.8, $95 \% \mathrm{Cl} 3.1$ to 19.6, no p-value reported $)^{50}$.

\section{Age}

Four out of seven studies reported younger individuals to be less vaccine willing 49,54,61,62. However, there were substantial variations in the age groupings used by included studies. Two studies reported individuals aged $<30$ years ${ }^{49}$ and $<35$ years old ${ }^{62}$ to be the least willing age group to receive the vaccine (OR 1.5 , $95 \% \mathrm{Cl} 1.3-1.9, \mathrm{p}<0.001$ and $\mathrm{OR} 1.2,95 \% \mathrm{Cl} 1.1-1.5, \mathrm{p}<0.001$ respectively). One study opposed this trend, reporting individuals aged $35-44$ years as most likely to reject $(\mathrm{OR} 3.3,95 \% \mathrm{Cl} 1.2-9.5, \mathrm{p}<0.05)^{56}$. Another conflicting study drew conclusions from proportions alone, suggesting individuals aged $<35$ years old were more vaccine willing than those in older age groups ${ }^{44}$.

\section{Time of Survey}

Across the 11 studies adopting a large sample size $(n \geq 1,000)$, the proportion reporting vaccine acceptance reduced significantly over time $46,47,49,52,53,55,58,60,61,62,64$. The nine surveys conducted between March-June had a pooled mean proportion of $76.8 \%$ survey participants reporting vaccine acceptance $(n=9,95 \% \mathrm{Cl} 68.5-84.1 \%, p=0.0)^{46,47,49,52,53,55,58,62,64}$ compared to $39.1 \%$ survey participants reporting vaccine acceptance $(n=2,95 \% \mathrm{Cl} 39.1-$ $40.5 \%, p=0.0)$ across the two studies conducted between July-December (Fig. 4$)^{60,61}$. Smaller studies $(n<1,000)$ were more likely to increase the heterogeneity of the results, so following the example of Robinson et al. ${ }^{24}$, the authors chose to restrict the subgroup analysis to larger studies which may have had more robust estimates of vaccine acceptance.

\section{Sampling Type}

A subgroup analysis assessing study methodology used for recruitment reveals that survey participants recruited via probability sampling $50,54,55,60,62$ were significantly less willing to receive the COVID-19 vaccine than survey participants recruited via non-probability sampling ${ }^{43,46-49,52,53,57,58,61,63-65}$ ( $p=0.029$, Fig.5), $55.6 \%$ (95\% Cl 34.0-76.1\%) compared to $79.3 \%(95 \% \mathrm{Cl} 73.0-85.1 \%)$ respectively.

Reasons for Vaccine Hesitancy

Concern over vaccine safety was the most common reason reported for both vaccine hesitancy and rejection cited in all six studies investigating vaccine reasoning $47,50,53,54,58,63$. Three studies explicitly stated that fears of potential side-effects were the main cause for concern ${ }^{53,54,58}$. 0 ther reasons include concern over vaccine efficacy ${ }^{53,58}$, speed of vaccine production and lack of evidence ${ }^{47,62}$, a lack of trust in both scientific and governmental bodies ${ }^{65}$, and 
general anti-vaccination attitudes ${ }^{47,62}$. For all studies investigating reasons for vaccine willingness, the main justification for vaccine acceptance was for the protection of both the individual and others ${ }^{47,53,63}$.

\section{Discussion}

\section{Comparison to Existing Literature}

Guidance on how to achieve high vaccine uptake could be based on existing evidence regarding uptake of previous vaccines and specific research on COVID19 vaccine intention. This systematic review investigated intentions to receive the COVID-19 vaccination across the global population and the relevant influencing factors, as reported in eligible international cross-sectional studies published between March and December 2020 . A total of 4739 journal articles were screened and 23 cross-sectional surveys were selected for inclusion in the review ${ }^{43-65}$. Twenty-one out of the twenty-three studies reported high intentions to receive the vaccine across survey participants ${ }^{43-54,56-59,61-65}$, with a significant trend towards a declining willingness to vaccinate over time; concordant with the findings of existing reviews investigating COVID-19 vaccine willingness ${ }^{20-24}$. Consistent with similar reviews, the main reasons behind COVID-19 vaccine acceptance reported in this review are for the protection of oneself and others, suggesting that receiving the vaccine is regarded as a social responsibility ${ }^{20-24}$.

Compared to self-reported acceptance to receive past-vaccines, the rate of COVID-19 vaccine acceptance was generally higher ${ }^{68-70}$. It is important to note the significant effect of sampling bias on self-reported vaccine acceptance in surveys included in the review. The inclusion of cross-sectional studies that used non-probability recruitment methods may have further limited the generalisability of the review findings to the general population.

Risk perception is a well-established determinant in vaccine decision-making ${ }^{71,72}$. This pattern of behaviour is reported as being no different for the COVID-19 vaccine and can be explained by the Health Belief Model; individuals are more likely to engage in health-protective behaviours if they perceive themselves to be at a higher risk from the disease in question ${ }^{73,74}$. The high level of uncertainty towards the threat of COVID-19 and rapid rate of transmission of the virus substantially increased individuals' perceived risk of ill-health and state of anxiety during the pandemic, motivating individuals to perform health-protective behaviours $^{75-77}$.

This review confirms the majority of findings reflected in existing literature investigating the sociodemographic trends in COVID-19 vaccine acceptance with higher educational attainment and household income, older age and being of White ethnicity to be associated with a higher acceptance ${ }^{20-24}$. Furthermore, this pattern is consistent with literature investigating attitudes towards past-vaccines ${ }^{78-81}$. Literature investigating past-vaccines consistently reports that females are likely to express higher vaccine acceptance in general compared to males 82,83 . However, the findings of this review investigating attitudes towards the COVID-19 vaccine report the opposite. Research has suggested that females are more likely to lower their intention to vaccinate following exposure to vaccine misinformation than males. The widespread conspiracy that the COVID-19 vaccine causes infertility may have contributed to this significant difference 84,85 . This same misconception posed an obstacle to uptake of the Polio vaccine in Nigeria, India and Pakistan ${ }^{86}$. Females are more likely to express greater levels of concern towards their personal health than males which could explain why females are more inclined to believe COVID-19 vaccine conspiracies ${ }^{87}$. Social media is reported to be the main source of vaccine misinformation ${ }^{88}$. The narrative of social media is rapidly changing, suggesting that the influence of social media on vaccine intentions is subject to change. The findings of this review are supported by two recent systematic reviews conducted in $2021^{22,23}$. Interestingly, Lin et al.'s narrative review reported inconsistent findings towards the influence of sex on COVID-19 vaccine acceptance ${ }^{20}$. Similarly, Robinson et al. stated that whilst seven out of fourteen studies reported that females have significantly lower COVID-19 vaccine intentions than males, five studies reported no significant association between COVID-19 vaccine acceptance and sex ${ }^{21}$.

\section{Further Research}

This review has contributed to the literature in providing the most recent representation of the public's views towards the COVID-19 vaccine around the globe. The findings of this review suggest that global policymakers cannot rely on the findings of existing literature about past-vaccines to formulate public health campaigns regarding COVID-19 vaccine uptake. Despite similar social pressures and the influence of risk perception on the uptake of both existing vaccines and the COVID-19 vaccine, there are several sociodemographic aspects specific to the COVID-19 vaccine that need to be considered and further researched, particularly in terms of sex and age. Public attitudes towards the COVID-19 vaccine around the globe need to be continuously explored as there appears to be evidence that attitudes can change rapidly, for example, the influence of social media on differences in vaccine acceptance between males and females. Consequently, we cannot rely solely on existing findings of past-vaccines and early COVID-19 vaccine research to guide government advice.

Both the UK and USA government are planning for a booster vaccine programme, as the duration of protection provided by the vaccine is currently unknown ${ }^{89,90}$. There are currently no surveys investigating intentions and motivation to receive a booster vaccination. This must be investigated and closely monitored by public health officials to guarantee the success of the vaccine and achieve herd immunity.

\section{Translation into Practice}

Following the subsequent roll-out of mass-vaccination programmes across the globe, uptake of the COVID-19 vaccine has been higher than anticipated. As of August 2021 , Israel has successfully vaccinated over $70 \%$ of all adults over the age of $16^{91}$ and the UK has almost achieved $80 \%$ of all adults over the age of 16 double vaccinated ${ }^{92}$. The literature suggests there are considerable discrepancies between decision-making in real-life and hypothetical situations, with individuals more likely to focus on the outcome of decisions in real-life situations ${ }^{93}$. As evidenced in this review, a major reason behind an individual's intention to receive the COVID-19 vaccine may be the protection of others as well as themselves. This suggests that receiving the vaccine may be seen as a 
social responsibility ${ }^{94}$. The UK no longer recommends the use of AstraZeneca in under-40s with no underlying health conditions following reports that the AstraZeneca vaccine may have a higher risk of blood clots than other vaccines ${ }^{95-97}$. However, this association was later disproved following a review by the European Medicines Agency ${ }^{98}$. Nevertheless, the Pfizer vaccine is the only vaccine authorised for young adults aged $12-17$ years old in the UK ${ }^{99}$ and numerous European countries have stopped administering the AstraZeneca vaccine across all age-groups ${ }^{100}$. It is important to acknowledge the political implications that Brexit may have had on the decision of the European Union to discontinue the use of AstraZeneca, a UK-made vaccine ${ }^{101,102}$. This decision may have fuelled vaccine hesitancy, with several European polls reporting a substantial drop in perceived vaccine safety following the AstraZeneca blood clot scares $^{101}$. Following the development of several licenced vaccines, vaccine acceptability and personal risk perceptions may be further affected by the type of vaccine offered to individuals. Thus, the reporting of vaccine risk assessments must be carefully navigated and the prevention of vaccine misinformation across social media is imperative if a high vaccine uptake is to be achieved across the globe.

This review has identified sub-groups of the population that are at a higher risk of vaccine hesitancy and low vaccine uptake. There is therefore a continued risk of pockets of local outbreaks across sub-groups of the population despite the vaccine now being available ${ }^{103}$. The findings of this review can guide local policy-makers towards the close monitoring of vaccine uptake amongst sub-groups of the population at risk of vaccine hesitancy, now vaccines are available. This review has highlighted the dangerous impact that vaccine misinformation can have on vaccine hesitancy, and thus can be used by local policy-makers to control the spread of COVID-19 misinformation on social media, focusing particularly on debunking COVID-19 vaccine myths targeted towards individuals at a higher risk of vaccine hesitancy. This review contributes to the growing evidence base suggesting that males are more likely to receive the COVID-19 vaccine than females ${ }^{22,23}$, opposing the trend in past-vaccine hesitancy across the sexes reported in existing literature ${ }^{82,83}$.

Strengths and Limitations

This systematic review has several strengths. Multiple databases were searched and there was a high level of agreement between screeners. Thorough quality and risk of bias assessments were also undertaken using validated tools that were piloted before use. However, searches were limited to English language studies and grey literature was explicitly excluded to ensure a manageable volume of literature was retrieved. This may have led to the exclusion of relevant literature. It is important to acknowledge the fast-moving nature of the COVID-19 pandemic; four licenced vaccines are now available whereas there were either no/limited vaccines available at the time when eligible studies were conducted ${ }^{104}$. The availability of vaccines may have a role in vaccine intentions.

\section{Conclusion}

Overall, the review discovered positive attitudes towards the COVID-19 vaccine before February 2021, with $73 \%$ of the total survey participants reporting a high intention to receive the COVID-19 vaccine. COVID-19 vaccine acceptance can be influenced by many sociodemographic factors and individual risk perception towards COVID-19. The findings of this review imply that future research should explore the reasoning behind vaccine intentions for different sociodemographic groups, to allow targeted communication strategies to be formulated by governments and public health agencies. The impact of both vaccine availability and reported adverse effects must be monitored so public health policies can address these concerns. A high vaccine uptake to current mass-vaccination programmes and potential booster vaccinations is essential to achieve the end goal of herd immunity and combat any potential future variants.

\section{Abbreviations}

\begin{tabular}{|ll|}
\hline Abbreviation & Meaning \\
\hline COVID-19 & Coronavirus Disease 2019 \\
\hline WHO & World Health Organisation \\
\hline UK & United Kingdom \\
\hline A/H1N1 & Diphtheria-tetanus-pertussis Vaccine \\
\hline PHE & Influenza A Virus subtype H1N1 \\
\hline CI & Confidence Interval \\
\hline SPIDER & Sample, Phenomenon of Interest, Design, Evaluation, Research Type \\
\hline PICO & Population, Intervention, Comparison, Outcomes \\
\hline AXIS & Appraisal Tool for Cross-Sectional Studies \\
\hline USA & United States of America \\
\hline BAME & Black, Asian and minority ethnic \\
\hline OR & Odds Ratio \\
\hline RRR & Relative Risk Ratio \\
\hline NHS & National Health System \\
\hline
\end{tabular}




\section{Declarations}

\section{Ethics Approval and Consent to Participate}

Not Applicable

\section{Consent for Publication}

Not Applicable

\section{Availability of Data and Materials}

Not Applicable

\section{Competing Interests}

The authors declare they have no competing interests.

\section{Funding}

Not applicable

\section{Authors' Contributions}

ET undertook the literature searches, all stages of screening, data-extraction and quality and risk of bias assessment. ET analysed and interpreted the survey data and was responsible for the writing of the manuscript.

SC participated in both independent title and abstract and full-text screening of eligible papers, and independently undertook quality and risk of bias assessment for $10 \%$ of studies.

SD participated in the resolution of screening, quality and risk of bias assessment disagreements between ET and SC and advised throughout all stages of searching, data collection and extraction, and data analysis. SD participated in decisions regarding the review focus, search strategy and points of discussion.

SG participated in decisions regarding the focus of the review, search strategy and points of discussion.

All authors read and approved the final manuscript.

\section{Acknowledgements}

I would like to thank the Public Health and Population Sciences team (Dr Laura Jones, Dr Derek Ward, Dr Jayne Parry) for their advice throughout this review, and Dr Benjamin Fletcher at the Institute of Applied Health Research for support with statistical analysis.

\section{Additional information}

Not Applicable.

\section{References}

1. World Health Organisation. Archived: WHO Timeline - COVID-19. [internet]. 2021 [cited 2021 April 20]. Available from: https://www.who.int/news/item/2704-2020-who-timeline--covid-19.

2. Bhowmick N. How India's second wave became the worst COVID-19 surge in the world. [internet]. 2021 [cited 2021 April 20]. Available from: https://www.nationalgeographic.com/science/article/how-indias-second-wave-became-the-worst-covid-19-surge-in-the-world

3. NHS. News NHS vaccine programme 'turning point' in battle against the pandemic. [internet]. 2020 [cited 2021 April 20]. Available from: https://www.england.nhs.uk/2020/12/nhs-vaccine-programme-turning-point-in-battle-against-the-pandemic/.

4. Randolph HE, Barreiro LB. Herd Immunity: Understanding COVID-19. Immunity. [internet]. 2020 [cited 2021 April 27];52(5):737-741. Available from: https://www.ncbi.nlm.nih.gov/pmc/articles/PMC7236739/

5. World Health Organisation. Coronavirus disease (COVID-19): Herd immunity, lockdowns and COVID-19. [internet]. 2020 [cited 2021 April 27]. Available from: https://www.who.int/news-room/q-a-detail/herd-immunity-lockdowns-and-covid-19.

6. Walensky RP, Walke HT, Fauci AS. SARS-CoV-2 variants of concern in the United States. JAMA. [internet].2021 [cited 2021 August 10];325(11):1037-1038. Available from: https://jamanetwork.com/journals/jama/fullarticle/2776739 
7. Aschwanden C. Five reasons why COVID herd immunity is probably impossible. Nat Med. [internet]. 2021 [cited 2021 May 5];591(7851):520-522. Available from: https://pubmed.ncbi.nIm.nih.gov/33737753/

8. Darby AC, Hiscox JA. Covid-19: variants and vaccination. BMJ. [internet]. 2021 [cited 2021 May 5];372:n771. Available from: https://www.bmj.com/content/372/bmj.n771

9. Pew Research Center U.S Politics \& Policy. Public Trust in Government: 1958-2021. [internet]. 2021 [cited 2021 May 10]. Available from: https://www.pewresearch.org/politics/2021/05/17/public-trust-in-government-1958-2021/

10. Evans RJ. Why pandemic create conspiracy theories. NewStatesman: Coronavirus. [internet]. 2020 [cited 2021 May 7]. Available from: https://www.newstatesman.com/science-tech/coronavirus/2020/04/why-pandemics-create-conspiracy-theories

11. Fletcher R, Kalogeropoulos A, Nielsen RK. Trust in UK government and news media COVID-19 information down, concerns over misinformation from government and politicians up. [internet]. 2020 [cited 2021 May 10]. Available from: https://reutersinstitute.politics.ox.ac.uk/trust-uk-government-andnews-media-covid-19-information-down-concerns-over-misinformation

12. Davidson M. Vaccination as a cause of autism-myths and controversies. Dialogues Clin Neurosci. [Internet]. 2017 [cited 2021 May 7];19(4):403-7. Available from: https://www.ncbi.nlm.nih.gov/pmc/articles/PMC5789217/

13. Burki T. The online anti-vaccine movement in the age of COVID-19. Lancet Digit Health. [internet]. 2020 [cited 2021 May 8];2(10):504-505. Available from: https://www.ncbi.nlm.nih.gov/pmc/articles/PMC7508526/

14. Islam S, Kamal AM, Kabir A, Southern DL, Khan SH, Hasan SMM et al. COVID-19 vaccine rumors and conspiracy theories: The need for cognitive inoculation against misinformation to improve vaccine adherence. PLoS One. [internet]. 2021 [cited 2021 May 8];16(5):e0251605. Available from: https://journals.plos.org/plosone/article?id=10.1371/journal.pone.0251605

15. MacDonald NE. Vaccine hesitancy: Definition, scope and determinants. Vaccine. [internet]. 2015 [cited 2021 May 10];33(34):4161-4164. Available from: https://pubmed.ncbi.nlm.nih.gov/25896383/

16. Baker JP. The pertussis vaccine controversy in Great Britain, 1974-1986. Vaccine. [internet]. 2003 [cited 2021 May 13];21(25-26):4003-4010. Available from: https://pubmed.ncbi.nlm.nih.gov/12922137/

17. Robinson RJ. The whooping-cough immunisation controversy. Arch Dis Child. [internet]. 1981 [cited 2021 May 13];56:577-580. Available from: https://adc.bmj.com/content/archdischild/56/8/577.full.pdf

18. Okoli GN, Lam OLT, Racovitan F, Reddy VK, Righolt CH, Neilson C et al. Seasonal influenza vaccination in older people: A systematic review and metaanalysis of the determining factors. PLoS One. [internet]. 2020 [cited 2021 May 14];15(6):e0234702. Available from: https://journals.plos.org/plosone/article?id=10.1371/journal.pone.0234702

19. Public Health England. Disparities in the risk and outcomes of COVID-19. [internet]. 2020 [cited 2021 April 20]. Available from: https://assets.publishing.service.gov.uk/government/uploads/system/uploads/attachment_data/file/908434/Disparities_in_the_risk_and_outcomes_of_C

20. Lin C, Tu P, Beitsch L. Confidence and Receptivity for COVID-19 Vaccines: A Rapid Systematic Review. Vaccines. [internet]. 2021 [cited 2021 April 25];9(1):16. Available from: https://www.mdpi.com/2076-393X/9/1/16

21. Robinson E, Jones A, Lesser I, Daly M. International estimates of intended uptake and refusal of COVID-19 vaccines: A rapid systematic review and metaanalysis of large nationally representative samples. Vaccine. [internet]. 2021 [cited 2021 April 25];39(15):2024-2034. Available from:

https://www.sciencedirect.com/science/article/pii/S0264410X21001407?via\%3Dihub

22. Wang Q, Yang L, Jin H, Lin L. Vaccination against COVID-19: A systematic review and meta-analysis of acceptability and its predictors. Prev Med. [internet]. 2021 [cited 2021 August 19];150:106694. Available from: https://www.ncbi.nlm.nih.gov/pmc/articles/PMC8217737/

23. Joshi A, Kaur M, Kaur R, Grover A, Nash D, El-Mohandes A. Predictors of COVID-19 Vaccine Acceptance, Intention, and Hesitancy: A Scoping Review. Front Public Health. [internet]. 2021 [cited 2021 August 19];(9):698111. Available from: https://doi.org/10.3389/fpubh.2021.698111

24. Wake AD. The Willingness to Receive COVID-19 Vaccine and Its Associated Factors: "Vaccination Refusal Could Prolong the War of This Pandemic" - A Systematic Review. Risk Manag Healthc Policy. [internet]. 2021 [cited 2021 August 19];(14):2609-2623. Available from: https://doi.org/10.2147/RMHP.S311074

25. Li T, Higgins JPT, Deeks JJ (editors). Chapter 5: Collecting data. In: Higgins JPT, Thomas J, Chandler J, Cumpston M, Li T, Page MJ, Welch VA (editors). Cochrane Handbook for Systematic Reviews of Interventions version 6.2 (updated February 2021). Cochrane, 2021. Available from .

26. Waffenschmidt S, Knelangen M, Sieben W, Buhn S, Pieper D. Single screening versus conventional double screening for study selection in systematic reviews: a methodological systematic review. BMC Med Res Methodol.[internet]. 2019 [cited 2021 May 10];19:132. Available from: https://bmcmedresmethodol.biomedcentral.com/articles/10.1186/s12874-019-0782-0

27. O'Connor D, Green S, Higgins JPT (editors). Chapter 5: Defining the review question and developing criteria for including studies. In: Higgins JPT, Green S (editors), Cochrane Handbook of Systematic Reviews of Intervention. Version 5.1.0 (updated March 2011). The Cochrane Collaboration, 2011. Available from .

28. Page MJ, McKenzie JE, Bossuyt PM, Boutron I, Hoffmann TC, Mulrow CD, et al. The PRISMA 2020 statement: an updated guideline for reporting systematic reviews. BMJ. [internet]. 2021 [cited 2021 April 20];372:n71. Available from: https://www.bmj.com/content/372/bmj.n71

29. Wolters Kluwer. Ovid MEDLINE $®$ and In-Process \& Other Non-indexed citations 1946 to February 12,2021. [internet]. [cited 2021 February 12]. Available from: https://ovidsp.dc1.ovid.com/ovid-a/ovidweb.cgi

30. Wolters Kluwer. Ovid Embase 1974 to 2021 February 12. [internet]. [cited 2021 February 12]. Available from: https://ovidsp.dc1.ovid.com/ovida/ovidweb.cgi

31. EBSCO (Firm). CINAHL Plus. [internet]. [cited 2021 February 12]. Available from: https://www.ebsco.com/products/research-databases/cinahl-database 
32. Wolters Kluwer. APA PsycINFO 1967 to February Week 2 2021. [internet]. [cited 2021 February 12]. Available from: https://ovidsp.dc1.ovid.com/ovida/ovidweb.cgi

33. Wolters Kluwer. APA PsycArticles Full Text. [internet]. [cited 2021 February 12]. Available from: https://ovidsp.dc1.ovid.com/ovid-a/ovidweb.cgi

34. ProQuest (Firm). Sociological Abstracts. [internet]. [cited 2021 February 12]. Available from: https://www-proquestcom.ezproxye.bham.ac.uk/socabs/index?accountid=8630

35. ProQuest (Firm). Applied Social Sciences Index and Abstracts. [internet]. [cited 2021 February 12]. Available from: https://www-proquestcom.ezproxye. bham.ac.uk/assia?accountid $=8630$

36. MacDonald NE. Vaccine hesitancy: Definition, scope and determinants. Vaccine. [internet]. 2015 [cited 2021 August 02];33(34):4161-4164. Available from: https://doi.org/10.1016/j.vaccine.2015.04.036.

37. The EndNote Team [computer program]. EndNote X9. Philadelphia, PA: Clarivate; 2013.

38. Ouzzani M, Hammady H, Fedorowicz Z, Elmagarmid A. Rayyan - a web and mobile app for systematic reviews. Syst Revs. [internet]. 2016 [cited 2021 February 12];5:210. Available from: https://systematicreviewsjournal.biomedcentral.com/articles/10.1186/s13643-016-0384-4

39. Zoom. Video Conferencing, Web Conferencing, Webinars, Screen Sharing [Internet]. 2018 [cited 2021 April 22]. Available from: https://zoom.us/

40. Hartling L, Hamm M, Milne A. Validity and inter-rater reliability testing of Quality Assessment Instruments. [internet]. Rockville(MD): Agency for Healthcare Research and Quality (US); 2012. Table 2, Interpretation of Fleiss' kappa (K) (from Landis and Koch 1977: Available from: https://www.ncbi.nIm.nih.gov/books/NBK92295/table/methods.t2/

41. Downes MJ, Brennan ML, Williams HC, et al. Development of a critical appraisal tool to assess the quality of cross-sectional studies (AXIS). BMJ Open. [internet]. 2016 [cited 2021 April 22];6(12):e011458. Available from: https://pubmed.ncbi.nlm.nih.gov/27932337/

42. StataCorp [computer program]. Stata Statistical Software: Release 16. College Station, TX: StataCorp LLC; 2019.

43. Abdelhafiz AS, Mohammed Z, Ibrahim ME, Ziady HH, Alorabi M, Ayyad M et al. Knowledge, Perceptions, and Attitude of Egyptians Towards the Novel Coronavirus Disease (COVID-19). J Community Health. [internet]. 2020 [cited 2021 February 12];45:881-890. Available from:

https://www.ncbi.nlm.nih.gov/pmc/articles/PMC7173684/

44. Ali KF, Whitebridge S, Jamal MH, Alsafy M, Atkin SL. Perceptions, Knowledge and Behaviors Related to COVID-19 Among Social Media Users: CrossSectional Study. J Med Internet Res. [internet]. 2020 [cited 2021 February 12];22(9):e19913. Available from: https://www.jmir.org/2020/9/e19913/

45. Alley SJ, Stanton R, Browne M, To QG, Khalesi S, Williams SL et al. As the Pandemic Progresses, How Does Willingness to Vaccinate against COVID-19 Evolve?. Int J Environ Res Public Health. [internet]. 2021 [cited 2021 February 12];18(2):797. Available from: https://www.mdpi.com/16604601/18/2/797\#

46. Attwell K, Lake J, Sneddon J, Gerrans P, Blyth C, Lee J. Converting the maybes: Crucial for a successful COVID-19 vaccination strategy. PLoS One. [internet]. 2021 [cited 2021 February 12];16(1):e0245907. Available from: https://journals.plos.org/plosone/article?id=10.1371/journal.pone.0245907

47. Bell S, Clarke R, Mounier-Jack S, Walker JL, Paterson P. Parents' and guardians' views on the acceptability of a future COVID-19 vaccine: A multi-methods study in England. Vaccine. [internet]. 2020 [cited 2021 February 12];38(49):7789-7798. Available from:

https://www.ncbi.nlm.nih.gov/pmc/articles/PMC7569401/

48. Biasio LR, Boonaccorsi G, Lorini C, Pecorelli S. Assessing COVID-19 vaccine literacy: a preliminary online survey. Hum Vaccin Immunother. [internet]. 2020 [cited 2021 February 12];17(5):1304-1312. Available from: https://pubmed.ncbi.nlm.nih.gov/33118868/

49. Detoc M, Bruel S, Frappe P, Tardy B, Botelho-Nevers E, Gagneux-Brunon A. Intention to participate in a COVID-19 vaccine clinical trial and to get vaccinated against COVID-19 in France during the pandemic. Vaccine. [internet]. 2020 [cited 2021 February 12];38(45):7002-7006. Available from:

https://www.ncbi.nlm.nih.gov/pmc/articles/PMC7498238/

50. Fisher KA, Bloomstone SJ, Walder J, Crawford S, Fouayzi H, Mazor KM. Attitudes Toward a Potential SARS-CoV-2 Vaccine: A Survey of U.S. Adults. Ann Intern Med. [internet]. 2020 [cited 2021 February 12];173(12):964-973. Available from: https://pubmed.ncbi.nlm.nih.gov/32886525/

51. Garcia LY, Cerda AA. Contingent assessment of the COVID-19 vaccine. Vaccine. [internet]. 2020 [cited 2021 February 12];38(34):5424-5429. Available from: https://www.ncbi.nlm.nih.gov/pmc/articles/PMC7315946/

52. Harapan H, Wagner AL, Yufika A, Winardi W, Anwar S, Gan AK et al. Willingness-to-pay for a COVID-19 vaccine and its associated determinants in Indonesia. Hum Vaccin Immunother. [internet]. 2020 [cited 2021 February 12];16(12):3074-3080. Available from:

https://www.tandfonline.com/doi/full/10.1080/21645515.2020.1819741

53. Lin Y, Hu Z, Zhao Q, Alias H, Danaee M, Wong LP. Understanding COVID-19 vaccine demand and hesitancy: A nationwide online survey in China. PLoS Negl Trop Dis. [internet]. 2020 [cited 2021 February 12];12(12):e0008961. Available from: https://journals.plos.org/plosntds/article? id=10.1371/journal.pntd.0008961

54. Mercadante AR, Law AV. Will they, or Won't they? Examining patients' vaccine intention for flu and COVID-19 using the Health Belief Model. Res Social Adm Pharm. [internet]. 2020 [cited 2021 February 12];20(1551-7411). Available from:

https://www.sciencedirect.com/science/article/pii/S1551741120312407?via\%3Dihub

55. Mouchtouri VA, Agathagelidou E, Kofonikolas K, Rousou X, Dadouli K, Pinaka O et al. Nationwide Survey in Greece about Knowledge, Risk Perceptions, and Preventive Behaviors for COVID-19during the General Lockdown in April 2020. Int J Environ Res Public Health. [internet]. 2020 [cited 2021 February 12];17(23):8854. Available from: https://pubmed.ncbi.nlm.nih.gov/33260789/

56. Murphy J, Vallieres F, Bentall RP, Shevlin M, McBride O, Hartman TK et al. Psychological characteristics associated withCOVID-19 vaccine hesitancy and resistance in Ireland and the United Kingdom. Nat Commun. [internet]. 2021 [cited 2021 February 12];12(29). Available from:

https://www.nature.com/articles/s41467-020-20226-9

Page $11 / 17$ 
57. Prati G. Intention to receive a vaccine against SARS-CoV-2 in Italy and its association with trust, worry and beliefs about the origin of the virus. Health Educ Res. [internet]. 2020 [cited 2021 February 12];35(6):505-511. Available from: https://pubmed.ncbi.nlm.nih.gov/33367772/

58. Reiter PL, Pennell ML, Katz ML. Acceptability of a COVID-19 vaccine among adults in the United States: How many people would get vaccinated? Vaccine. [internet]. 2020 [cited 2021 February 12];38(42):6500-6507. Available from: https://www.ncbi.nlm.nih.gov/pmc/articles/PMC7440153/

59. Romer D, Jamieson KH. Conspiracy theories as barriers to controlling the spread of COVID-19 in the U.S. Soc Sci Med. [internet]. 2020 [cited 2021 February 12];263:113356. Available from: https://pubmed.ncbi.nlm.nih.gov/32967786/

60. Sallam M, Dababseh D, Eid H, Al-Mahzoum K, Al-Haidar,A, Taim D et al. High Rates of COVID-19 Vaccine Hesitancy and Its Association with Conspiracy Beliefs: A Study in Jordan and Kuwait among Other Arab Countries. Vaccines. [internet]. 2021 [cited 2021 February 12];9(1):42. Available from: https://pubmed.ncbi.nlm.nih.gov/33445581/

61. Sherman SM, Smith LE, Sim J, Amlôt R, Cutts M, Dasch H et al. COVID-19 vaccination intention in the UK: results from the COVID-19 vaccination acceptability study (CoVAccS), a nationally representative cross-sectional survey. Hum Vaccin Immunother. [internet]. 2020 [cited 2021 February 12];17(6):1612-1621. Available from: https://pubmed.ncbi.nlm.nih.gov/33242386/

62. Ward JK, Alleaume C, Peretti-Watel P. The French public's attitudes to a future COVID-19 vaccine: The politicization of a public health issue. Soc Sci Med. [internet]. 2020 [cited 2021 February 12];265:113414. Available from: https://www.ncbi.nlm.nih.gov/pmc/articles/PMC7537647/

63. Williams L, Gallant AJ, Rasmussen S, Nicholls LAB, Cogan N, Deakin K et al. Towards intervention development to increase the uptake of COVID-19 vaccination among those at high risk: Outlining evidence-based and theoretically informed future intervention content. Br J Health Psychol. [internet]. 2020 [cited 2021 February 12];25(4):1039-1054. Available from: https://bpspsychub.onlinelibrary.wiley.com/doi/10.1111/bjhp.12468

64. Wong LP, Alias H, Wong PF, Lee HY, AbuBakar S. The use of the health belief model to assess predictors of intent to receive the COVID-19 vaccine and willingness to pay. Hum Vaccin Immunother. [internet]. 2020 [cited 2021 February 12];16(9):2204-2214. Available from:

https://pubmed.ncbi.nlm.nih.gov/32730103/

65. Zeballos DR, Jaldin MLL, Canaviri BN, Escalante LFP, Fernandez AMCA, Ticona JPA.Social media exposure, risk perception, preventive behaviors and attitudes during the COVID-19 epidemic in La Paz, Bolivia: A cross sectional study. PLoS One. [internet]. 2021 [cited 2021 February 12];16(1):e0245859. Available from: https://journals.plos.org/plosone/article?id=10.1371/journal.pone.0245859

66. Gavi The Vaccine Alliance. The COVID-19 vaccine race - weekly update. [internet]. 2020 [cited 2021 May 10]. Available from: https://www.gavi.org/vaccineswork/covid-19-vaccine-race

67. DeRoo SS, Pudalov NJ, Fu LY. Planning for a COVID-19 Vaccination Program. JAMA Netw Open [internet]. 2020 [cited 2021 May 10];323(24):2458-2459. Available from: https://jamanetwork.com/journals/jama/fullarticle/2766370

68. European Centre for Disease Prevention and Control. Season influenza vaccination in Europe Vaccination recommendations and coverage rates in the EU Member States for eight influenza seasons: 2007-2008 to 2014-2015. [internet]. 2017 [cited 2021 May 8]. Available from:

https://www.ecdc.europa.eu/sites/default/files/documents/influenza-vaccination-2007\%E2\%80\%932008-to-2014\%E2\%80\%932015.pdf

69. Perlman S, Wamai RG, Bain PA, Welty T, Ogembo JG. Knowledge and Awareness of HPV Vaccine and Acceptability to Vaccinate in Sub-Saharan Africa: A Systematic Review. PLoS One [internet]. 2014 [cited 2021 May 12];9(3):e90912. Available from: https://journals.plos.org/plosone/article? id=10.1371/journal.pone.0090912

70. Public Health England. Seasonal influenza vaccine uptake in GP patients: winter season 2018 to 2019. [internet]. 2019 [cited 2021 May 10]. Available from:

https://assets.publishing.service.gov.uk/government/uploads/system/uploads/attachment_data/file/804889/Seasonal_influenza_vaccine_uptake_in_GP

71. Hobson-West P. Understanding vaccination resistance: moving beyond risk. Health Risk Soc. [internet]. 2012 [cited 2021 May 10];5(3):273-283. Available from: https://www.tandfonline.com/doi/abs/10.1080/13698570310001606978?journalCode=chrs20

72. Dube E, MacDonald NE. The Vaccine Book edition 2. Academic Press; 2016. (Chap. 26 - Vaccine Acceptance: Barriers, Perceived Risks, Benefits, and Irrational Beliefs).

73. LaMorte W. The Health Belief Model [Internet]. 2019 [cited 2021 May 10]. Available from: https://sphweb.bumc.bu.edu/otlt/MPHModules/SB/BehavioralChangeTheories/BehavioralChangeTheories2.html

74. Schneider CR, Dryhurst S, Kerr J, Freeman ALJ, Recchia G, Spiegelhalter D et al. COVID-19 risk perception: a longitudinal analysis of its predictors and associations with health protective behaviours in the United Kingdom. J Risk Res. [internet]. 2021 [cited 2021 May 10];24(3):294-313. Available from: https://www.tandfonline.com/doi/full/10.1080/13669877.2021.1890637

75. World Health Organisation. Modes of transmission of virus causing COVID-19: implications for IPC precaution recommendations. [internet]. 2020 [cited 2021 April 10]. Available from: https://www.who.int/news-room/commentaries/detail/modes-of-transmission-of-virus-causing-covid-19-implications-foripc-precaution-recommendations

76. McCleskey J, Gruda D. Risk-taking, resilience, and state anxiety during the COVID-19 pandemic: A coming of (old) age story. Pers Individ Dif. [internet]. 2021 [cited 2021 May 10];170:110485. Available from: https://www.sciencedirect.com/science/article/pii/S0191886920306760

77. Oyetunji TP, Ogunmola OA, Oyelakin TT, Olorunsogbon OF, Ajayi FO. COVID-19-related risk perception, anxiety and protective behaviours among Nigerian adults: a cross-sectional study. Z Gesundh Wiss. [internet]. 2021 [cited 2021 May 11]:1-9. Available from:

https://www.ncbi.nlm.nih.gov/pmc/articles/PMC7950426/

78. NHS. COVID-19 vaccine programme Maximising vaccine uptake in undeserved communities: a framework for systems, sites and local authorities leading vaccination delivery. [internet]. 2021 [cited 2021 May 9]. Available from: https://www.england.nhs.uk/coronavirus/wpcontent/uploads/sites/52/2021/03/C1226-maximising-vaccine-uptake-in-underserved-communities-a-framework-.pdf 
79. GOVUK. Factors influencing COVID-19 vaccine uptake among minority ethnic groups. [internet]. 2021 [cited 2021 April 10]. Available from: https://assets.publishing.service.gov.uk/government/uploads/system/uploads/attachment_data/file/952716/s0979-factors-influencing-vaccine-uptakeminority-ethnic-groups.pdf

80. National Institute for Health and Care Excellence. Flu vaccination: increasing uptake. NICE guidelines NG103 [internet]. London: National Institute for Health and Care Excellence; 2018 [cited 2021 May 2]. Available from: https://www.nice.org.uk/guidance/ng103/chapter/Context

81. Fajar JK, Harapan H. Socioeconomic and Attitudinal Variables Associated with Acceptance and Willingness to Pay Towards Dengue Vaccine: A Systematic Review. Arch Clin Infect Dis. [internet]. 2017 [cited 2021 May 5];12(3):e13914. Available from:

https://sites.kowsarpub.com/archcid/articles/13914.html

82. Figueiredo A, Simas C, Karafillakis E, Paterson P, Larson HJ. Mapping global trends in vaccine confidence and investigating barriers to vaccine uptake: a large-scale retrospective temporal modelling study. Lancet [internet]. 2020 [cited 2021 May 11];396(10255):898-908. Available from:

https://www.thelancet.com/journals/lancet/article/PIIS0140-6736(20)31558-0/fulltext

83. Harapan H, Anwar S, Setiawan AM, Sasmono RT. Dengue vaccine acceptance and associated factors in Indonesia: A community-based cross-sectional survey in Aceh. Vaccine. [internet]. 2016 [cited 2021 May 11];34(32):3670-3675. Available from:

https://www.sciencedirect.com/science/article/pii/S0264410X16303164?via\%3Dihub

84. Fossett K. The myth about women and the Covid-19 vaccine that won't die. [internet]. 2021 [cited 2021 May 6]. Available from: https://www.politico.com/newsletters/women-rule/2021/03/26/the-myth-about-women-and-the-covid-19-vaccine-that-wont-die-492263

85. Hamel L, Kirzinger A, Lopes L, Kearney A, Sparks G, Brodie M. KFF COVID-19 Vaccine Monitor: January 2021. [internet]. 2021 [cited 2021 May 7]. Available from: https://www.kff.org/report-section/kff-covid-19-vaccine-monitor-january-2021-vaccine-hesitancy/

86. Obregon R, Chitnis K, Morry C, Feek W, Bates J, Galway M et al. Achieving polio eradication: a review of health communication evidence and lessons learned in India and Pakistan. Bull World Health Organ. [internet]. 2009 [cited 2021 May 7];87:624-630. Available from: https://www.who.int/bulletin/volumes/87/8/08-060863.pdf

87. Prichard EC, Christman SD. Authoritarianism, Conspiracy Beliefs, Gender and COVID-19: Links Between Individual Differences and Concern About COVID19, Mask Wearing Behaviors, and the Tendency to Blame China for the Virus. Front Psychol. [internet]. 2020 [cited 2021 May 5];11:3130. Available from: https://www.frontiersin.org/article/10.3389/fpsyg.2020.597671

88. The Royal Society. COVID-19 vaccine deployment: Behaviour, ethics, misinformation and policy strategies. [internet]. 2020 [cited 2021 May 4]. Available from: https://royalsociety.org/-/media/policy/projects/set-c/set-c-vaccine-deployment.pdf

89. Public Health England. UK secures extra 60 million Pfizer/BioNTech COVID-19 vaccines [press release]. [internet]. 2021 [cited 2021 April 28 ]. Available from: https://www.gov.uk/government/news/uk-secures-extra-60-million-pfizerbiontech-covid-19-vaccines

90. CNBC. CDC director says U.S. is planning for Covid vaccine booster shots 'just in case'. [internet]. 2021 [cited 2021 May 26 ]. Available from: https://www.cnbc.com/2021/05/11/covid-booster-shots-cdc-director-says-us-planning-just-in-case.html

91. Israel Ministry of Health. Coronavirus in Israel - general situation. [internet]. 2021 [cited 2021 May 26]. Available from: https://datadashboard.health.gov.il/COVID-19/general

92. GOV.UK. Coronavirus (COVID-19) in the UK - UK Summary. [internet]. 2021 [cited 2021 August 26]. Available from: https://coronavirus.data.gov.uk/

93. Evans AM, Brand MJ. Comparing the Effects of Hypothetical Moral Preferences on Real-Life and Hypothetical Behavior: Commentary on Bostyn, Sevenhant, and Roets (2018). Adv Methods Pract Psychol Sci. [internet]. 2019 [cited 2021 May 15];30(9):1380-1382. Available from: https://journals.sagepub.com/doi/full/10.1177/0956797618815482

94. Giubilini A, Douglas T, Savulescu J. The moral obligation to be vaccinated: utilitarianism, contractualism, and collective easy rescue. Med Health Care Philos. [internet]. 2018 [cited 2021 May 6];21(4):547-560. Available from: https://www.ncbi.nlm.nih.gov/pmc/articles/PMC6267229/

95. Public Health England. JCVI advises on COVID-19 vaccine for people aged under 40 [press release]. [internet]. 2021 May 7 [cited 2021 May 26 ]. Available from: https://www.gov.uk/government/news/jcvi-advises-on-covid-19-vaccine-for-people-aged-under-40

96. Public Health England. COVID-19 vaccination and blood clotting. [internet]. 2021 [cited 2021 August 24]. Available from: nhs.uk/CoronavirusVaccination

97. Pavord S, Scully M, Hunt BJ, Lester W. Clinical Features of Vaccine-Induced Immune Thrombocytopenia and Thrombosis. N Engl J Med. [internet]. 2021 [cited 2021 August 24]; . Available from: https://pubmed.ncbi.nlm.nih.gov/34379914/

98. European Medicines Agency. COVID-19 Vaccine AstraZeneca: benefits still outweigh the risks despite possible link to rare blood clots with low blood platelets. [internet]. 2021 [cited 2021 August 26]. Available from: https://www.ema.europa.eu/en/news/covid-19-vaccine-astrazeneca-benefits-stilloutweigh-risks-despite-possible-link-rare-blood-clots

99. Department of Health \& Social Care. JCVI statement on COVID-19 vaccination of children and young people aged 12 to 17 years: 4 August 2021. [internet]. 2021 [cited 2021 August 26]. Available from: https://www.gov.uk/government/publications/jcvi-statement-august-2021-covid-19-vaccination-ofchildren-and-young-people-aged-12-to-17-years/jcvi-statement-on-covid-19-vaccination-of-children-and-young-people-aged-12-to-17-years-4-august-2021

100. PharmaNewsIntelligence. European Countries Suspend Use of AstraZeneca's COVID-19 Vaccine. [internet]. 2021 [cited 2021 August 24 ]. Available from: https://pharmanewsintel.com/news/european-countries-suspend-use-of-astrazenecas-covid-19-vaccine

101. Smith M. Extent of damage to AstraZeneca vaccine's perceived safety in Europe revealed. [internet]. 2021 [cited 2021 August 26 ]. Available from: https://yougov.co.uk/topics/international/articles-reports/2021/03/07/extent-damage-astrazeneca-vaccines-perceivedsafet(popup:related_entities/correlated/Richard_Branson)

102. BBC News. Covid vaccine: How many people in the UK have been vaccinated so far?. [internet]. 2021 [cited 2021 August 26]. Available from: https://www.bbc.co.uk/news/health-55274833

Page $13 / 17$ 
103. British Science Association. Vaccine hesitancy and false alarms. [internet]. 2021 [cited 2021 August 26]. Available from:

https://www.britishscienceassociation.org/blog/vaccine-hesitancy

104. NHS. Coronavirus (COVID-19) vaccines. [internet]. 2021 [cited 2021 August 26]. Available from: https://www.nhs.uk/conditions/coronavirus-covid19/coronavirus-vaccination/coronavirus-vaccine/

\section{Figures}

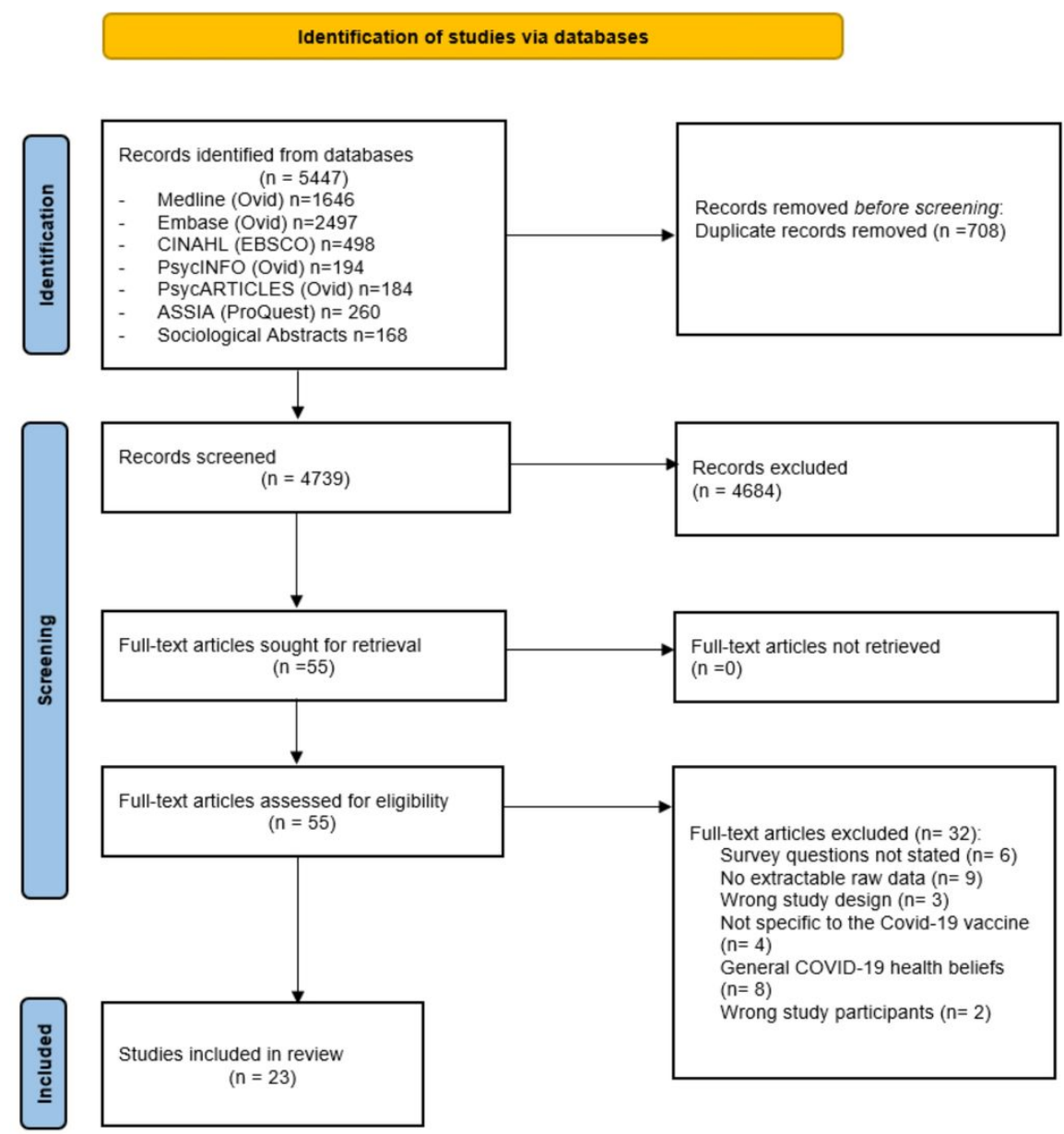

Figure 1. PRISMA Flow Diagram illustrating the summary of search strategy results from initial search to included studies ${ }^{28}$.

\section{Figure 1}

PRISMA Flow Diagram illustrating the summary of search strategy results from initial search to included studies28. 
Study

Estimated Proportion (\%) of Survey

Participants reporting Vaccine

'acceptance' (95\% Cl)

Abedlhafiz et al. (2020)

Atwell et al. (2021)

Bell et al. (2020)

Biasio et al. (2020)

Detoc et al. (2020)

Fisher et al. (2020)

Harapan et al. (2020)

Lin et al. (2020)

Mercadante et al. (2020)

Mouchtouri et al. 2020

Prati et al. (2020)

Reiter et al. (2020)

Sallam et al. (2021)

Sherman et al. (2020)

Ward et al. (2020)

Williams et al. (2020)

Wong et al. (2020)

Zeballos et al. (2021)

Overall $\left(I^{\wedge} 2=99.66 \%, p=0.00\right)$

$88.55(85.64,90.93)$

$64.44(61.81,66.98)$

- $90.10(88.32,91.63)$

$92.20(90.25,93.79)$

$77.63(76.17,79.03)$

$57.62(54.52,60.66)$

- $93.30(91.85,94.51)$

- $\quad 83.48(82.22,84.67)$

$66.67(62.53,70.57)$

$48.06(45.80,50.34)$

$75.80(72.29,79.00)$

$68.99(66.93,70.98)$

$28.71(27.21,30.25)$

$64.00(61.54,66.39)$

76.01 (74.81, 77.17)

$85.39(82.12,88.15)$

78.00 (75.52, 80.29)

$54.29(51.00,57.54)$

$73.26(64.19,81.45)$

\begin{tabular}{c|c|c|cc} 
& & & \\
-50 & 1 & 50 & 100 & 150
\end{tabular}

Figure 2

Random-effects meta-analysis of 18 cross-sectional studies43,46-50,52-55,57,58,60-64: Estimated proportion of survey participants reporting vaccine acceptance (\% of total sample). Vaccine 'acceptance' is defined as either definite (responding 'yes/ accepting/ strongly agree/ very likely') or possible (responding 'agree/ probably yes/ somewhat likely/ unsure but leaning towards yes'). Vaccine 'unwillingness' is defined as hesitant (responding 'not sure/ neither agree nor disagree/ neutral/ I don't know/ Maybe/ Hesitant), improbable (responding 'somewhat unlikely/ disagree/ unsure but leaning towards no/ probably no) or very improbable (responding 'no/ very unlikely/ strongly disagree/ resistant). $\mathrm{Cl}=$ confidence interval. 


$$
\text { Group } 2 \text { - Male }
$$

Atwell et al. (2020)

Fisher et al. (2020)

Lin et al. (2020)

Reiter et al. (2020)

Sallam et al. (2021)

Ward et al. (2020)

Wong et al. (2020)

Subtotal $\left(I^{\wedge} 2=99.22 \%, p=0.00\right)$

Group 1 - Female

Atwell et al. (2020)

Fisher et al. (2020)

Lin et al. (2020)

Reiter et al. (2020)

Sallam et al. (2021)

Ward et al. (2020)

Wong et al. (2020)

Subtotal $\left(I^{\wedge} 2=99.77 \%, p=0.00\right)$

Heterogeneity between groups: $p=0.247$

Overall $\left(I^{\wedge} 2=99.67 \%, p=0.00\right)$;

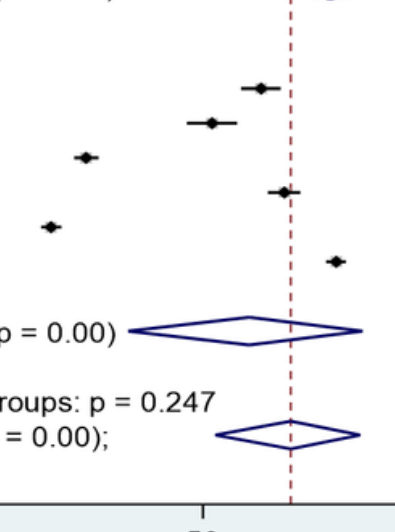

50 $(95 \% \mathrm{Cl})$

Figure 3

Subgroup analysis by gender of 7 studies46,50,53,58,60,62,64: Estimated proportion of survey participants reporting COVID-19 vaccine acceptance (\% of total sample in each gender group). Group 1=Female Participants, Group 2=Male Participants, $\mathrm{Cl}=$ confidence interval. Seven studies presented proportions of total survey participants willing to receive the COVID-19 vaccine by gender and hence data was collated in a subgroup analysis. Response proportions were combined into 2 categories; vaccine 'acceptance' (responding with either strongly agree or agree to receiving the COVID-19 vaccine) and vaccine 'unwillingness' (responding with either maybe, disagree, strongly disagree to receiving the COVID-19 vaccine).

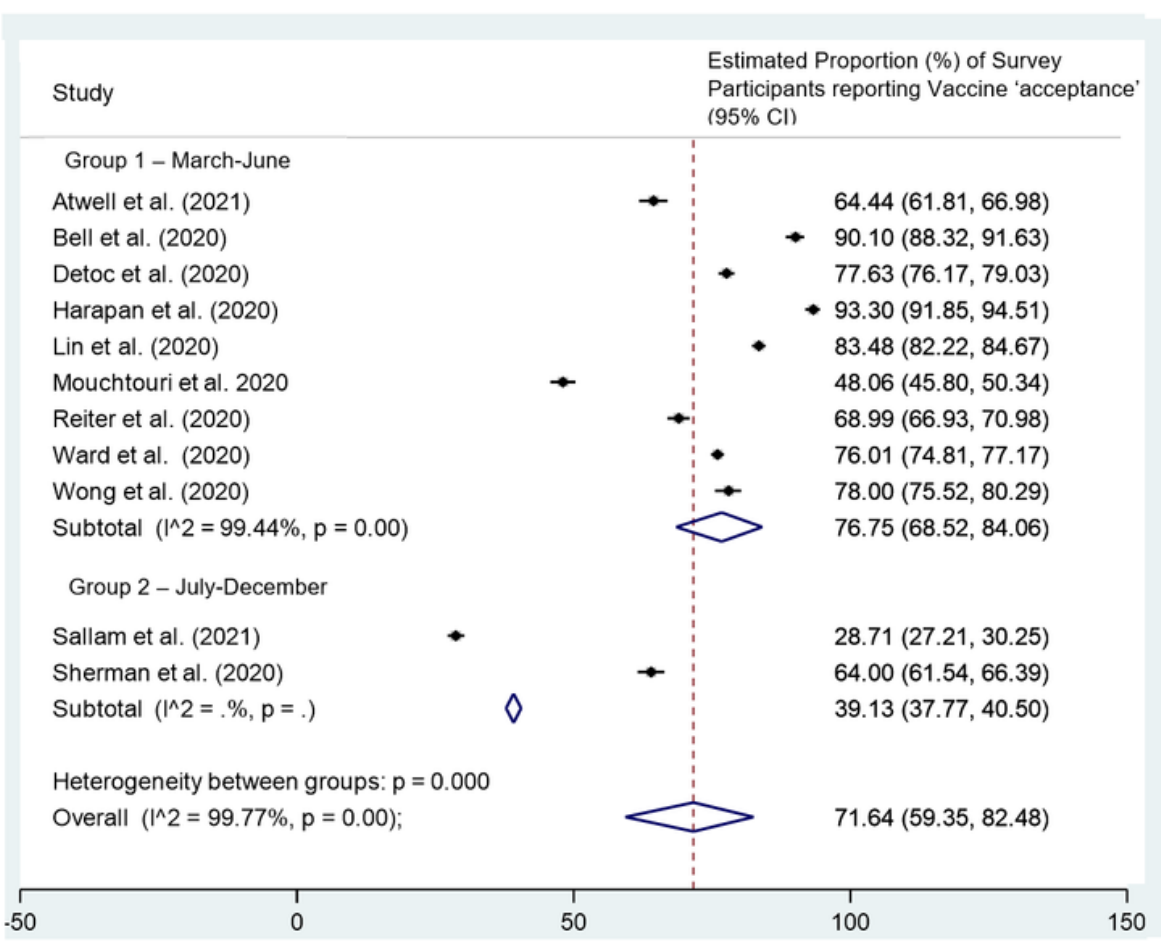


Figure 4

Subgroup analysis by time of survey of 11 studies $46,47,49,52,53,55,58,60,61,62,64$ : Estimated proportion of survey participants reporting COVID-19 vaccine acceptance (\% of total sample). Only the 11 studies with a sample size $\geq 1,000$ were included in the analysis. Group 1=March-June 2020, Group 2=JulyDecember 2020, $\mathrm{Cl}=$ Confidence Interval.

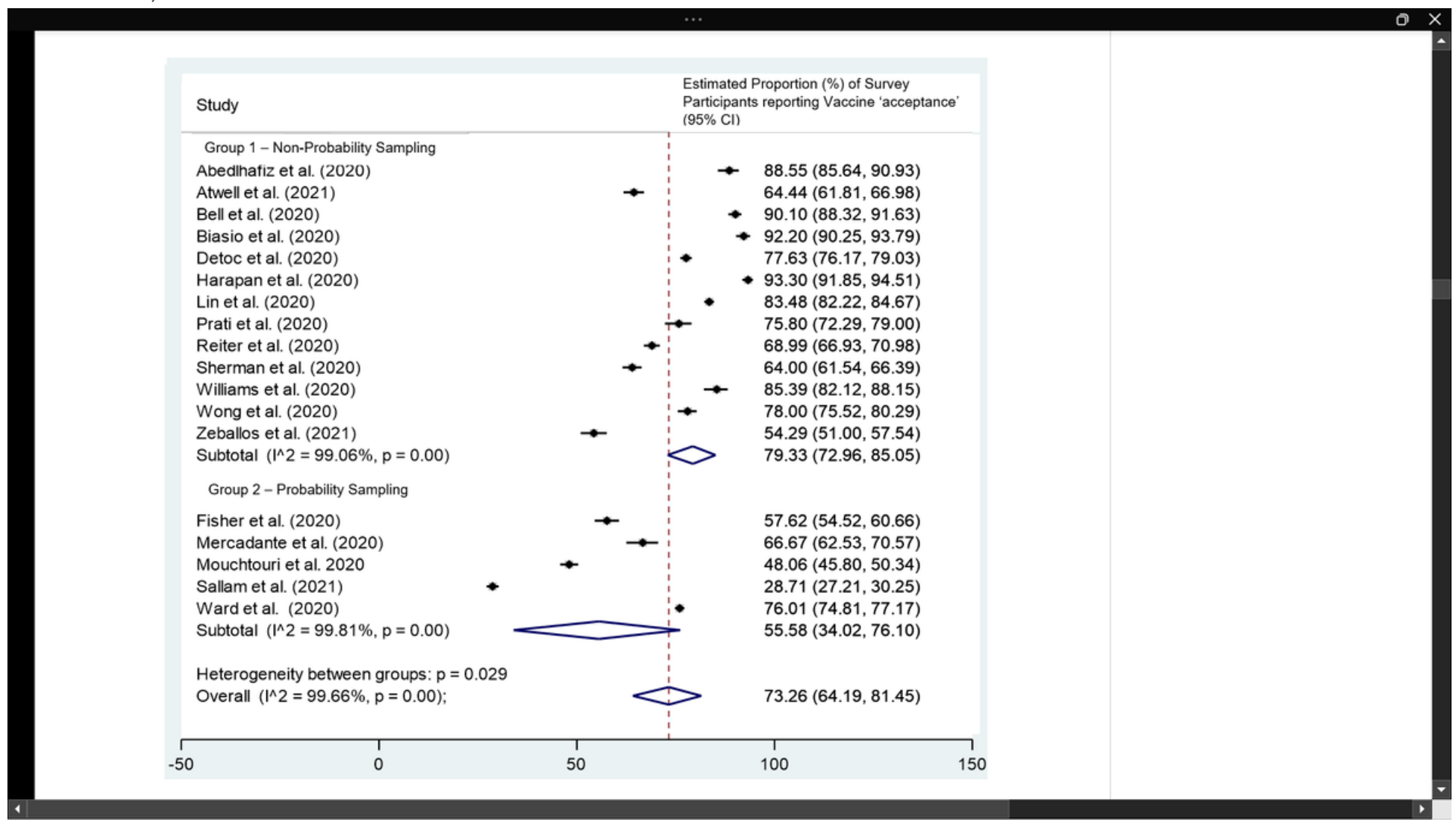

Figure 5

Subgroup analysis of vaccine acceptance by method of recruitment of 18 studies43,46-50,52-55,57,58,60-64: (ES) estimated proportion of total survey participants reporting COVID-19 vaccine acceptance (\% of total sample). 1=Non-Probability Sampling, 2=Probability Sampling, Cl= Confidence Interval .

\section{Supplementary Files}

This is a list of supplementary files associated with this preprint. Click to download.

- AdditionalFile1.docx

- AdditionalFile2.docx

- AdditionalFile3.docx

- AdditionalFile4.docx

- AdditionalFile5.docx 